\title{
Communications
}

\section{Patterned Fluorescence Images Based on a Retro Diels-Alder Reaction}

\author{
Bora Yoon and Jong-Man Kim*

\begin{abstract}
Department of Chemical Engineering, Hanyang University, Seoul 133-791, Korea. *E-mail: jmk@hanyang.ac.kr Received October 13, 2010, Accepted November 18, 2010
\end{abstract}

Key Words: Fluorescence patterning, Retro Diels-Alder reaction, Photo acid generator (PAG)

Recently, Miller and his coworker reported a Diels-Alder (DA) reaction between 1,3-diphenylnaphtho[2,3-c]furan (1) and $p$-benzoquinone (2) (Scheme 1). ${ }^{1,2}$ They were able to obtain a single diastereomeric compound $\mathbf{3}$ in high yield from the double DA reaction within a few min at room temperature. Interestingly, the DA adduct 3 was found to undergo a dehydration reaction efficiently in the presence of acid to yield the quinone 4 . The acid-catalyzed dehydration step in Scheme 1 draws our special attention. Close inspection of the structures 3 and 4 reveals an intriguing aspect. Owing to the diepoxy bridge structure, the compound $\mathbf{3}$ does not have an extended $\pi$-conjugation. In contrast, the dehydrated quinone $\mathbf{4}$ exists as a fully conjugated form with extended overlap of p-orbitals. Thus, a red shift of maximum absorption wavelength of the quinone $\mathbf{4}$ is expected compared with that of DA adduct 3 .

In the course of the development of wet process-free micropatterning methodologies studied in our group ${ }^{3-5}$ and others, ${ }^{6-10}$ we came up with an intriguing idea of generating patterned functional images based on the DA and acid-catalyzed dehydration reactions. If the conversion from DA adduct 3 to quinone 4 could be achieved by a photolithographic method, selective DA adduct-to-quinone transformation would be possible. In addition, if the two molecules $\mathbf{3}$ and $\mathbf{4}$ display different absorption or/and emission properties, fabrication of color or/and fluorescence image patterns should be possible.

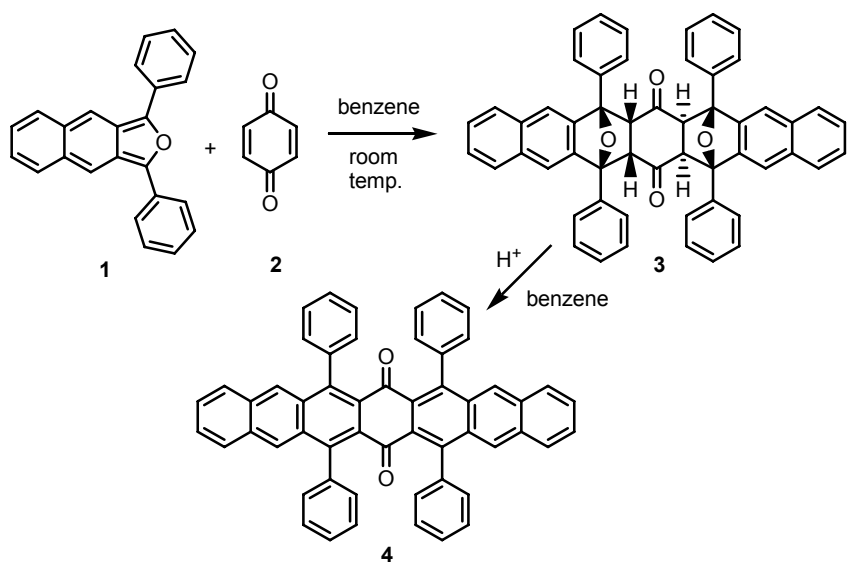

Scheme 1. Synthesis of quinone 4 based on the DA reaction followed by dehydration process

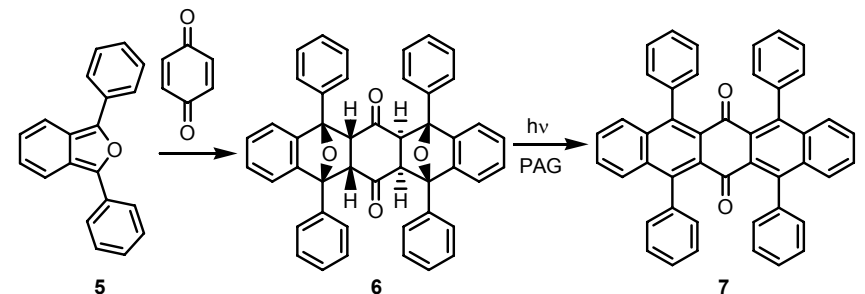

Scheme 2. Preparation of DA adduct 6 and its photochemical conversion to quinone 7

In order to test the above proposal, we have prepared an analogous yet readily obtainable (synthesis of furan 1 in Scheme 1 requires multistep efforts) DA adduct 6. As shown in Scheme 2, a DA reaction between commercially available 1,3-diphenylisobenzofuran (5) and $p$-benzoquinone lead to the formation of DA adduct $6 .{ }^{11}$ We expected the structurally non-fluorescent DA adduct 6 to be transformed to quinone 7 by photochemically generated acid using photoacid generator (PAG). If the fully conjugated quinone 7 emits fluorescence, fabrication of patterned fluorescence images should be possible.

In order to test the feasibility of fluorescence patterning, a chloroform solution containing the DA adduct 6 (19 wt \%), poly(methylmethacrylate) (PMMA) (80 wt \%), and triphenylsulfonium triflate ( $1 \mathrm{wt} \%$ ) as a PAG was spin-coated at 3000 rpm for $20 \mathrm{sec}$ on a glass substrate. The resulting thin film was irradiated with UV light $\left(254 \mathrm{~nm}, 12 \mathrm{~mW} / \mathrm{cm}^{2}\right)$ for $10 \mathrm{~min}$ through a photomask, followed by post-exposure bake (PEB) at $100^{\circ} \mathrm{C}$ for $1 \mathrm{mim}$. Figure 1 displays the patterned fluorescence images under a fluorescence microscope. As shown in Figure 1,

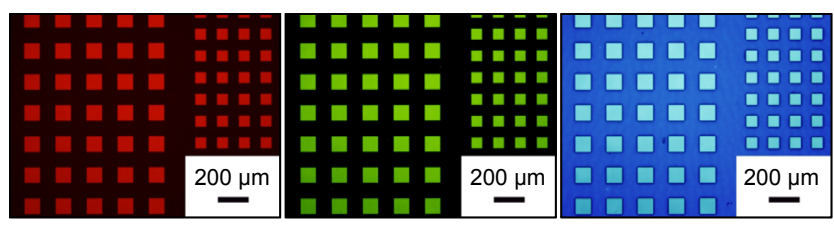

Figure 1. Patterned fluorescence images of a spin-coated film on a glass substrate containing 6 after photomasked irradiation with 254 $\mathrm{nm}\left(12 \mathrm{~mW} / \mathrm{cm}^{2}\right) \mathrm{UV}$ irradiation for $10 \mathrm{~min}$ and $\operatorname{PEB}\left(100{ }^{\circ} \mathrm{C}, 1 \mathrm{~min}\right)$ process. Excitation wavelength: red $(546 \mathrm{~nm})$, green $(488 \mathrm{~nm})$, and blue $(357 \mathrm{~nm})$, Exposure time: red $(1 / 3 \mathrm{sec})$, green $(1 / 3 \mathrm{sec})$, and blue $(1 / 10 \mathrm{sec})$. 


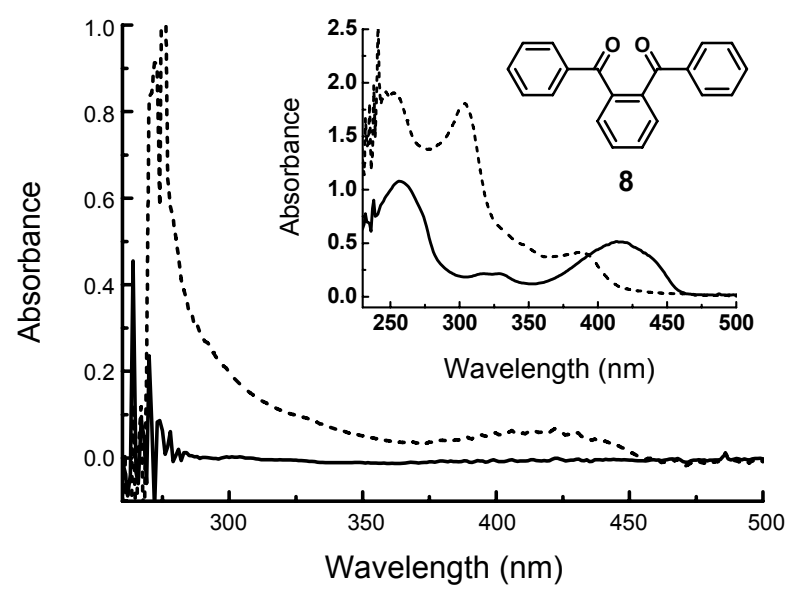

Figure 2. UV-visible absorption spectra obtained with a PMMA film containing DA adduct $6(19 \mathrm{wt} \%)$ and PAG $(1 \mathrm{wt} \%)$ before (solid line) and after (dotted line) $254 \mathrm{~nm}$ UV irradiation $\left(12 \mathrm{~mW} / \mathrm{cm}^{2}, 10\right.$ min) followed by PEB $\left(100^{\circ} \mathrm{C}, 1 \mathrm{~min}\right)$ process. Inset shows absorption spectra of furan 5 (solid line) and quinone 7 (dotted line) in $\mathrm{CHCl}_{3}\left(5 \times 10^{-5} \mathrm{M}\right)$

three fluorescence colors - red, green, and blue were observed from the UV-exposed areas.

We expected that the patterned images shown in Figure 1 were due to the generation of the quinone 7 in the UV exposed area. The quinone 7 was also prepared independently from the DA adduct 6 with $p$-toluenesulfonic acid. ${ }^{12}$ To our surprise, the main photochemical product from the UV irradiation in the presence of PAG was not the quinone 7. Instead, a retro DA reaction occurred efficiently and the highly fluorescent 1,3-diphenylisobenzofuran (5) was generated in the UV exposed area. Thus, the main contribution of the patterned fluorescence images shown in Figure 1 is caused by the furan $\mathbf{5}$. It is still unclear whether small amount of quinone $\mathbf{7}$ is indeed generated under the photolithographic condition. Figure 2 shows UV-visible absorption spectra of a PMMA film containing the DA adduct 6 and PAG obtained before (solid line) and after (dotted line) the UV irradiation-PEB process. A new absorption peak above $400 \mathrm{~nm}$, which is obviously different from the absorption spectrum of $\mathbf{7}$ and alternatively, similar to that of furan $\mathbf{5}$ was observed (see also inset in the figure). Purification of the retro Diels-Alder product 5 from the photoirradiated film was attempted and we only observed conversion of 5 to 1,2-dibenzoylbenzene (8) during the purification step. ${ }^{1} \mathrm{H}$ NMR spectra of the crude product and the commercially available $\mathbf{8}$ are presented in Figure S1. In addition, UV-visible spectra for 5, 6, 7, and 8 are also shown in Figure S2.

It is still unclear how the retro DA reaction occurs during the photoirradiation process. We also carried out the patterning process without employing PAG and obtained patterned images with poorer resolution and lower intensity of the fluorescence emission compared with those prepared in the presence of PAG (data not shown). Although it is hard to understand the detailed mechanism including the role of PAG involved with the photoinduced retro DA reaction, we nevertheless, believe that the strong UV light generated from the UV illuminator causes local heating and promote the retro DA reaction in the exposed area (possibly in the presence of the acid generated from PAG).

In summary, we have developed a new strategy for the generation of patterned fluorescence images in polymer film. Fluorescent molecules were produced in the UV exposed area. Although high quality image patterns were obtained by unexpected retro Diels-Alder reaction, it would be very intriguing if patterned images could be fabricated by photochemically generated acid-promoted dehydration of Diels-Alder adducts.

Acknowledgments. The authors gratefully thank National Research Foundation of Korea for financial support through Basic Science Research Program (20100018438), Center for Next Generation Dye-sensitized Solar Cells (20100001844), and International Research \& Development Program (K2090 1000006-09E0100-00610). This work is the outcome of a Manpower Development Program for Energy supported by the Ministry of Knowledge and Economy (MKE). B. Yoon is a recipient of Seoul City Scholarship.

\section{References and Notes}

1. Miller, G. P.; Briggs, J. Tetrahedron Lett. 2004, 45, 477.

2. Miller, G. P.; Briggs, J. Org. Lett. 2003, 5, 4203.

3. Kim, J.-M. Macromol. Rapid Commun. 2007, 28, 1191.

4. Lee, S.; Ahn, T.-Y.; Kim, S.; Jung, Y.-S.; Kim, J.-M. Bull. Korean Chem. Soc. 2010, 31, 2755.

5. Kim, J.; Lee, S.; Kim, J.-M. Bull. Korean Chem. Soc. 2010, 31, 2753.

6. Lim, S.-J.; Seo, J.; Park, S. Y.J. Am. Chem. Soc. 2006, 128, 14542.

7. Kwak, G.; Lee, W.-E.; Kim, W.-H.; Lee, H. Chem. Commun. 2009, 2112.

8. Lee, J. K.; Kim, H.-J.; Kim, T. H.; Lee, C.-H.; Park, W. H.; Kim, J.; Lee, T. S. Macromolecules 2005, 38, 9427.

9. Min, S.-J.; Ahn, K.-D.; Kim, J.-M. Bull. Korean Chem. Soc. 2005, 26, 1437.

10. Cho, S.-Y.; Song, Y.-K.; Kim, J.-G.; Oh, S.-Y.; Chung, Chan.-M. Tetrahedron Lett. 2009, 50, 4769.

11. 5,7,12,14-Tetraphenyl-5,14:7,12-dioxido-5,5a,6,6a,7,12,12a, $13,13 a, 14$-decahydro-6,13-pentacene quinone (6) was synthesized following modified procedure described in the literature (Allen, C. F. H.; Gates, J. W., Jr. J. Am. Chem. Soc. 1943, 65, 1502). 1,3-Diphenylisobenzofuran (5) was purchased from Aldrich. $p$-Benzoquinone $(0.1 \mathrm{~g}, 0.93 \mathrm{mmol})$ was added to a suspension of 1,3-diphenylisobenzoquinone (5) $(0.62 \mathrm{~g}, 2.31 \mathrm{mmol})$ in benzene $(40 \mathrm{~mL})$ and the resulting mixture was stirred at room temperature for 1 day. The suspension was filtered and washed with hexane to afford desired product $6(0.53 \mathrm{~g}, 89 \%)$. mp $192-194^{\circ} \mathrm{C}$; ${ }^{1} \mathrm{H} \mathrm{NMR}\left(300 \mathrm{MHz}\right.$, in $\left.\mathrm{CDCl}_{3}\right) \delta$ 7.83-7.80 (m, 4H), 7.64-7.62 $(\mathrm{m}, 6 \mathrm{H}), 7.26-7.18(\mathrm{~m}, 6 \mathrm{H}), 7.14-7.09(\mathrm{~m}, 4 \mathrm{H}), 7.05-7.02(\mathrm{~m}, 2 \mathrm{H})$, 6.92-6.89 (m, 2H), 6.68-6.65 (m, 4H), $4.33(\mathrm{~s}, 2 \mathrm{H}), 3.27(\mathrm{~s}, 2 \mathrm{H})$.

12. 5,7,12,14-Tetraphenylpentacene-6,13-quinone (7) was synthesized following modified procedure described in the literature (Allen, C. F. H.; Gates, J. W., Jr. J. Am. Chem. Soc. 1943, 65, 1502). A mixture of $6(1.0 \mathrm{~g}, 1.54 \mathrm{mmol}), p$-toluenesulfonic acid $(2.33 \mathrm{~g}$, $6.16 \mathrm{mmol}$ ) and benzene $(40 \mathrm{~mL})$ was heated to reflux for 2 days. The solution was washed with saturated aqueous sodium bicarbonate solution, water, and brine and then concentrated under reduced pressure. The solid residue was washed with acetone to afford the yellow powder 7 (0.07 g, 7.2\%). mp $397-398{ }^{\circ} \mathrm{C} ;{ }^{1} \mathrm{H}$ NMR $\left(300 \mathrm{MHz}\right.$, in $\left.\mathrm{CDCl}_{3}\right) \delta$ 7.62-7.58 (m, 4H), 7.45-7.41 (m, 4H), 7.40-7.35 (m, 6H), 7.28-7.24 (m, 4H). 